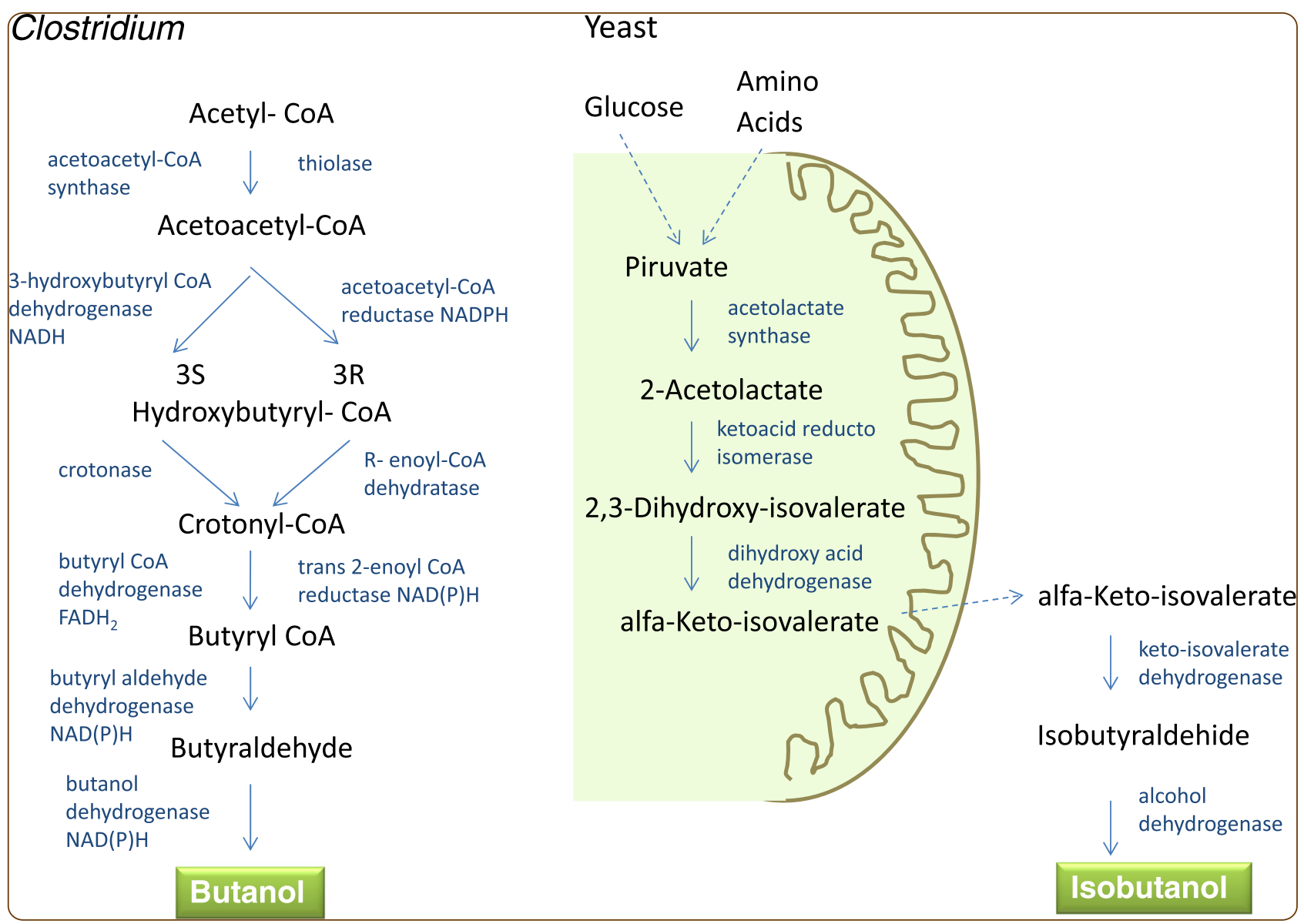

\title{
Biobutanol from cheese whey
}

Becerra et al. 


\title{
Biobutanol from cheese whey
}

\author{
Manuel Becerra, María Esperanza Cerdán and María Isabel González-Siso
}

\begin{abstract}
At present, due to environmental and economic concerns, it is urgent to evolve efficient, clean and secure systems for the production of advanced biofuels from sustainable cheap sources. Biobutanol has proved better characteristics than the more widely used bioethanol, however the main disadvantage of biobutanol is that it is produced in low yield and titer by ABE (acetone-butanol-ethanol) fermentation, this process being not competitive from the economic point of view. In this review we summarize the natural metabolic pathways for biobutanol production by Clostridia and yeasts, together with the metabolic engineering efforts performed up to date with the aim of either enhancing the yield of the natural producer Clostridia or transferring the butanol production ability to other hosts with better attributes for industrial use and facilities for genetic manipulation. Molasses and starch-based feedstocks are main sources for biobutanol production at industrial scale hitherto. We also review herewith (and for the first time up to our knowledge) the research performed for the use of whey, the subproduct of cheese making, as another sustainable source for biobutanol production. This represents a promising alternative that still needs further research. The use of an abundant waste material like cheese whey, that would otherwise be considered an environmental pollutant, for biobutanol production, makes economy of the process more profitable.

Keywords: Biobutanol, Cheese whey, Metabolic engineering, Clostridium, Yeast
\end{abstract}

\section{Introduction}

\section{Biobutanol as energy source}

The limited availability and rising price of fossil fuels, together with the growing concern on the greenhouse effect and the climate change, urge to evolve efficient, clean and secure systems for the production of advanced biofuels from sustainable cheap sources.

Nowadays bioethanol is the most widely used, blended with gasoline at various percentages, but biobutanol has proved better characteristics. The term biobutanol includes four butanol isomers: $n$-, sec-, tert- and, mainly, isobutanol with a low melting temperature and the highest octane number (a measure of anti-knock properties). Isobutanol and $n$-butanol are the most largely manufactured. Biobutanol energy value is similar to gasoline and $30 \%$ higher than ethanol; it can be used mixed with gasoline up to any level and even pure, while ethanol only can be used mixed with gasoline up to a limited level; since it is not hygroscopic, it can be blended with gasoline at the refinery, while ethanol and gasoline must

\footnotetext{
*Correspondence: migs@udc.es

Grupo EXPRELA, Centro de Investigacións Científicas Avanzadas (CICA), Departamento de Bioloxía Celular e Molecular, Facultade de Ciencias, Universidade da Coruña, Campus de A Coruña, 15071 A Coruña, Spain
}

be blended just before use; also it can be blended up to $40 \%$ with diesel or biodiesel and can be upgraded to aviation jet biofuel; biobutanol can be used without modification of existing automotive engines both in pure or blended forms; it is non-corrosive and then also the existing infrastructure of pipelines, tanks, pumps, etc. can be used; and finally its vapour pressure is lower than the one of ethanol, being therefore of safer handling [1-4].

Historically, the ABE (acetone-butanol-ethanol) fermentation process by solventogenic Clostridium species was industrially employed from the early $20^{\text {th }}$ century till the Second World War when it was replaced by the production from petroleum. The onset of the renaissance of fermentative production is dated about the $1980 \mathrm{~s}$, but up to the $21^{\text {st }}$ century butanol was used just as a bulk chemical; in 2005 the successful use of butanol in an unmodified car completely replacing gasoline was reported, and thereafter interest in biobutanol production for fuel use has been increasingly emphasized [5]. As an example, the web page http://www.biofuelstp. eu/butanol.html (date of reference 08/01/2015) mentions that in December 2013, the company Gevo announced successful trials by the US Army of a 50/50 blend of a Gevo's fuel in a helicopter. 
At present the main disadvantage of biobutanol is that its production through $\mathrm{ABE}$ fermentation is not cost-effective compared with other biofuels such as ethanol, since yield and titer of butanol are lower; therefore the improvement of substrates, microbial strains and processes for its costcompetitive production is a matter of priority research [4].

An approach to compare the range of yield and economics of biobutanol and bioethanol productions was made by Pfromm et al. in 2010 [6]. The authors compared the fermentative production of $n$-butanol vs. ethanol from corn or switchgrass in terms of the lower heating value (LHV) of the liquid fuel products per unit mass of the feedstock, and they found that the energy yield of butanol using ABE technology was about half of ethanol with both substrates. Reasons include that the ABE fermentation converts a substantial amount of carbon to acetone which cannot be used as a fuel, that ABE fermentation produces relatively more $\mathrm{CO}_{2}$ than yeast alcoholic fermentation, and that more starch remains unfermented. A given fermenter volume produced about one-quarter of the LHV as $n$-butanol per unit time compared to ethanol. They also report, in terms of carbon mass balance, industrially confirmed yields for fuel ethanol production by yeast equivalent to about $0.30 \mathrm{~kg}$ pure ethanol per $\mathrm{kg}$ corn and, for $\mathrm{ABE}$ fermentation by $C$. acetobutylicum, equivalent to about $0.11 \mathrm{~kg} n$-butanol per $\mathrm{kg}$ of corn $(3 \mathrm{~kg}$ of starch converted to $1 \mathrm{~kg}$ of mixed solvents with a weight ratio of $n$-butanol/acetone/ethanol of 6/3/1). Ethanol fermentation reaches about $15 \%$ (equivalent to $\sim 7 \%$ of ethanol saturation in water) while ABE fermentation reaches about $2 \%$ $n$-butanol (equivalent to $\sim 25 \%$ of $n$-butanol saturation in water). To equal the yeast based bio-ethanol process these authors estimate that $n$-butanol yield should increase from about 0.11 to $0.19 \mathrm{~kg} n$-butanol per $\mathrm{kg}$ corn. Even though during the last years diverse efforts to improve biobutanol fermentative production have been performed, as here reviewed, yield is still a bottle-neck [4] as long as feedstock costs can be the highest fraction of the overall production cost of bio-based liquid fuels; thus on a conventional plant, corn starch is reported to account for up to $79 \%$ of the overall solvent production cost [7].

Molasses and starch are main sources for butanol manufacture hitherto. However, molasses show a geographical limitation and starchy raw materials, such as corn and wheat, are food or feed supplies and then are not available for biofuels large-scale manufacture. Moreover, lignocellulosic residues that are plentiful and very cheap have been widely investigated but their recalcitrance to degradation, and the generation of inhibitors of the process, challenge production of butanol. So that alternative sustainable sources for biobutanol production are still needed [4]. A similar situation could be described for bioethanol production. Other waste materials, like cheese whey, that would otherwise be considered environmental pollutants can be converted into energy sources, thus making the pathway to a biofuel-based economy more feasible [8]. Cheese whey is already a substrate for bioethanol production at industrial scale [9] but its use for biobutanol production has been less investigated and needs further research, as here reviewed.

\section{Review}

The metabolic pathways in the production of biobutanol Natural producers of biobutanol

Clostridium species are natural producers of $n$-butanol through a biosynthetic pathway that depends on acetyl-CoA sources, the CoA-dependent pathway. Well-known species from Clostridia producing biobutanol are C. acetobutylicum, C. saccharoperbutylacetonicum, C. beijerinckii, C. saccharoacetobutylicum, C. aurantibutyricum, C. cadaveris, C. sporogenes, C. pasteurianum, and C. tetanomorphum. Among them, the first four species produced the highest yields [10]. In Clostridia acetyl-CoA is produced from diverse carbon sources, also including lactose, the sugar present in whey $[11,12]$. The fermentation of these sugars usually proceeds in batch mode in two phases. The first (acidogenesis) produces acetic and butyric acids and the second (solventogenesis) acetone, butanol and ethanol (thus named ABE fermentation). In the CoA-dependent pathway two acetyl-CoA molecules are used to generate a $\mathrm{C} 4$ molecule, followed by reduction into $n$-butanol. The enzymes, coenzymes and stereo-specificity of each reaction to produce $n$-butanol are shown in Figure 1. The first problem to make this process economically attractive for the production of biobutanol is that it is necessary to find a way to easily shift the metabolism of natural producers from the acidogenic phase towards solventogenesis. Besides, it is necessary to avoid the toxicity of the solvent products, which are mostly attributed to the action of butanol on the microbial cell membranes due to its chaotropic effect [13]. Butanol concentrations over $2 \%$ seriously compromise bacterial survival [14].

Another natural metabolic pathway for the production of biobutanol is by deviation of metabolic intermediates from the biosynthesis of aliphatic amino acids in yeast $[15,16]$. In some yeast species producing fusel alcohols as fermentation by-products, the Ehrlich pathway decarboxylates keto acids and produces aldehydes, which are finally reduced to alcohols. Since keto acids are the precursors of amino-acids, $n$-propanol is obtained from isoleucine, isobutanol from valine and $n$-butanol from norvaline pathways (Figure 1). Isobutanol is the preferred for industrial use because it has a better octane number than $n$-butanol. The industrial application is hampered by the very low intrinsic production in yeast. This route is 


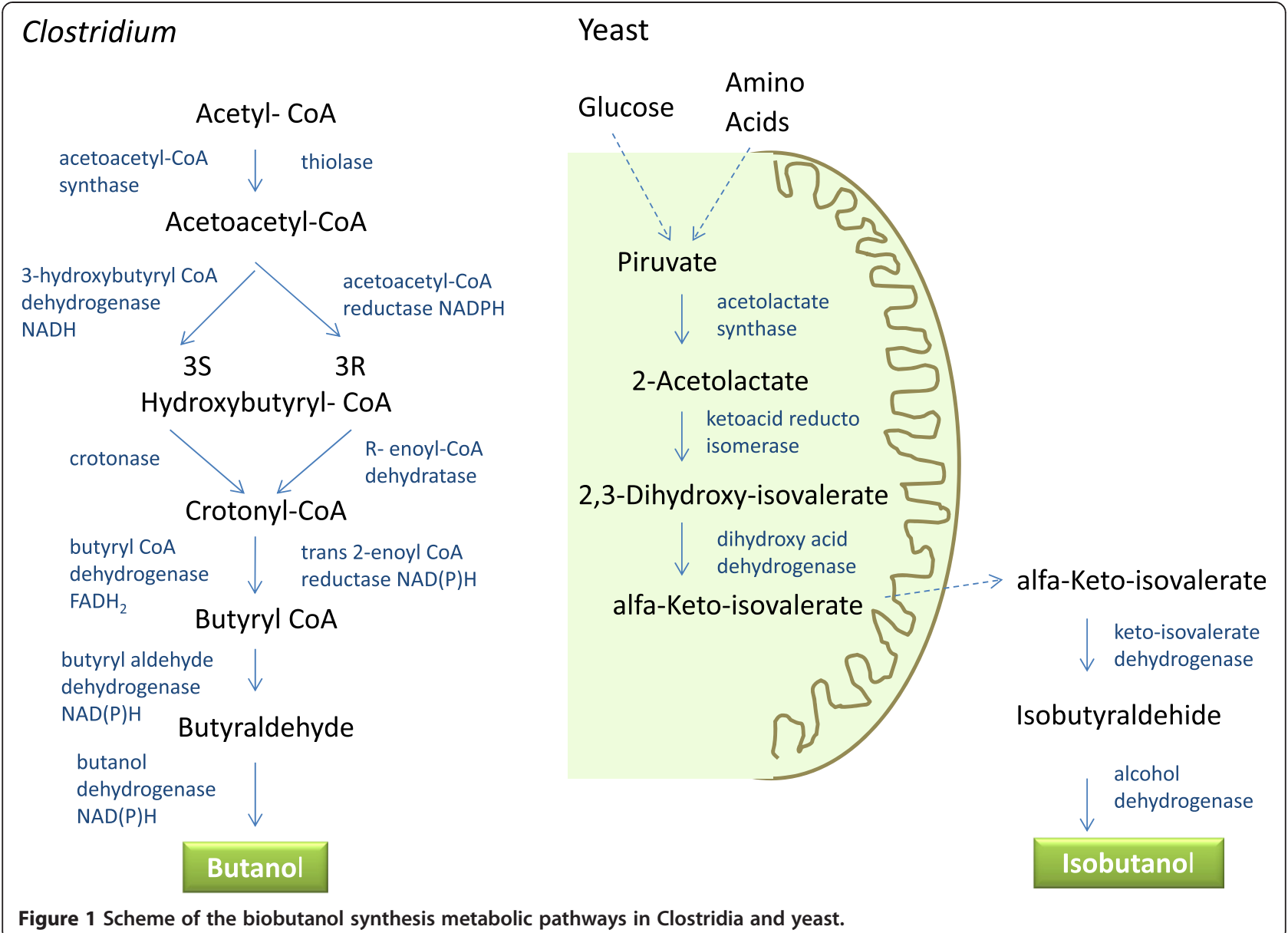

indeed disadvantageous for the cell since it diverts intermediates, which are necessary for amino acid biosynthesis and therefore it is not naturally favoured.

\section{Engineered pathways in bacteria}

Two main strategies for improving biobutanol production in bacteria can be considered. The first one is based on regulatory and metabolic engineering of bacteria from the Clostridia, and all attempts in this field aim to avoid undesired products and to increase the yield of alcohols obtained as well as the tolerance to butanol. The second one is the engineering of non-producer bacteria with heterologous pathways of biobutanol biosynthesis from natural producers or with artificially generated pathways combining enzymes from different genera. Table 1 summarizes the techniques employed, yield and productivity reached for butanol and $\mathrm{ABE}$.

\section{Towards a better solventogenic Clostridium producer}

Several attempts to improve C. acetobutylicum by mutagenesis were successful. A better tolerance to butanol, a higher yield and improved sugar source utilization were achieved by these approaches (reviewed in [5]). Several species of Clostridium have been also engineered in order to make possible the use of alternative carbon sources such as: liquefied corn flour [18], glycerol [19] and a mixture of hydrogen and carbon monoxide [20].

A direct way to improve fuel alcohols production is to avoid acetone formation in the ABE process [29,30]. This strategy has been pursued by inactivation of the adc gene, encoding the acetoacetate decarboxylase and necessary for acetone synthesis [21]. Another approach consists in obtaining isopropanol from acetone by metabolic engineering. The mixture of isopropanol, butanol, and ethanol (IBE) produced by engineered $C$. acetobutylicum is also useful as biofuel. The gene encoding the required dehydrogenase from $C$. beijerinckii and other genes have been transferred to C. acetobutylicum $[22,23]$. A recently reported IBE strain produces $99 \%$ of fuel alcohols with negligible amount of acetone [23]. Usually metabolic engineering is a pyramidal task in which the starting strain has been already obtained by improving metabolic fluxes and yield by a previous approach [23]. 
Table 1 Metabolic engineering approaches to improve biobutanol production by bacteria

\begin{tabular}{|c|c|c|c|}
\hline Bacteria and engineering technique & $\begin{array}{l}\text { Fuel concentration } \\
\text { g/L }\end{array}$ & $\begin{array}{l}\text { Productivity } \\
\text { g/L h }\end{array}$ & Reference \\
\hline Clostridium acetobutylicum not engineered & B: 8.3 & $\mathrm{nr}$ & [17] \\
\hline Clostridium beijerinckii engineered to use liquefied corn flour + product recovery & ABE: 81.3 & $\mathrm{nr}$ & [18] \\
\hline $\begin{array}{l}\text { Hyper butanol producing strain of Clostridium pasteurianum isolated by chemical } \\
\text { mutagenesis and optimized to produce butanol from glycerol in bach culture }\end{array}$ & B: 17.8 & B: 0.43 & [19] \\
\hline \multirow[t]{2}{*}{ Idem to previous in continuous culture } & \multirow[t]{2}{*}{$\mathrm{nr}$} & ABE: 8.30 & \multirow[t]{2}{*}{ [19] } \\
\hline & & B: 7.80 & \\
\hline Clostridium ljungdahlii engineered to use a mixture of hydrogen and carbon monoxide & \multicolumn{2}{|c|}{$\begin{array}{l}\text { butanol produced, but only detectable } \\
\text { during middle growth phase, then it } \\
\text { is metabolized to butyrate }\end{array}$} & [20] \\
\hline \multirow{2}{*}{$\begin{array}{l}\text { Clostridium acetobutylicum engineered by inactivation of the adc gene, encoding the } \\
\text { acetoacetate decarboxylase and necessary for acetone synthesis. }\end{array}$} & B: 14.8 & \multirow[t]{2}{*}{$\mathrm{nr}$} & \multirow[t]{2}{*}[21]{} \\
\hline & BE: 18.1 & & \\
\hline $\begin{array}{l}\text { Clostridium acetobutylicum engineered with a synthetic operon for obtaining isopropanol } \\
\text { from acetone }\end{array}$ & IBE: 35.6 & IBE 0.83 & [22] \\
\hline Clostridium acetobutylicum engineered for obtaining isopropanol from acetone & IBE: 27.9 & $\mathrm{nr}$ & [23] \\
\hline $\begin{array}{l}\text { Clostridium ljungdahlii transformed with a plasmid, carrying the C. acetobutylicum } \\
\text { butanol synthesis pathway genes }\end{array}$ & B: $0.15^{*}$ & & [24] \\
\hline \multirow{2}{*}{$\begin{array}{l}\text { Escherichia coli engineered to produce isopropanol and butanol with genes from } \\
\text { C. acetobutylicum and others }\end{array}$} & I: 4.9 & \multirow[t]{2}{*}{ I: $0.4 \mathrm{~B}: \mathrm{nr}$} & \multirow[t]{2}{*}{ [25] } \\
\hline & B: 0.5 & & \\
\hline Escherichia coli engineered to produce butanol with genes from C. acetobutylicum & B: $0.20-0.58$ & $\mathrm{nr}$ & [26] \\
\hline Pseudomonas putida engineered to produce butanol with genes from C. acetobutylicum & B: 0.12 & $\mathrm{nr}$ & {$[26]$} \\
\hline Bacillus subtilis engineered to produce butanol with genes from C. acetobutylicum & B: 0.02 & $\mathrm{nr}$ & [26] \\
\hline Lactobacillus brevis engineered to produce butanol with genes from C. acetobutylicum & B: 0.30 & $\mathrm{nr}$ & [17] \\
\hline Synthetic butanol pathway expressed in Escherichia coli & B: 4.65 & $\mathrm{nr}$ & [27] \\
\hline Modified Escherichia coli by the 2-keto-acid pathway & B: 20 & B: 0.18 & {$[25]$} \\
\hline Modified Corynebacterium glutamicum by the 2-keto-acid pathway & B: 4.9 & $\mathrm{nr}$ & [28] \\
\hline
\end{tabular}

*in the middle of the exponential growth phase but consumed by the organism (only $0-15 \mathrm{mg} / \mathrm{L}$ left at the end of growth)

A: Acetone; B: 1 or 2-butanol; E: Ethanol; I: Isopropanol; nr: not reported.

Towards artificially-generated bacterial producers

In the production of butanol by solventogenic Clostridia starchy substrates or molasses are consumed as carbon sources. To avoid competence with nutritional feedstock, an alternative is the utilization of gaseous substrates and acetogenic Clostridia [24]. Following this strategy C. ljungdahlii was transformed with a plasmid, carrying the genes thlA, hbd, crt, $b c d$, adhE, and $b d h A$ of the $C$. acetobutylicum butanol synthesis pathway; these genes encode the thiolase, 3-hydroxybutyryl-CoA dehydrogenase, crotonase, butyryl-CoA dehydrogenase, butanol/butyraldehyde dehydrogenase, and butanol dehydrogenase, respectively [20].

The introduction of the Clostridium butanol pathway into other bacteria that grow faster, are more resistant to butanol or metabolize alternative substrates might solve some of the limitations observed in Clostridium. Escherichia coli has a higher growth rate than Clostridia and has been engineered to produce butanol [25,31]. Pseudomonas putida that overcomes butanol toxicity by specific efflux pumps or Bacillus subtilis that becomes more resistant by changing its cell-wall composition are also selected hosts [26]. Lactobacillus brevis that has a high tolerance to butanol, and is able to digest C5 and C6 substrates, has also been used [17].

The production of butanol is principally limited by the intrinsic kinetic characteristics and cofactor specificity of the enzymes of the natural Clostridium pathway, with independence of the selected host organism. This limitation can be overcome by using a synthetic pathway. This has been done by combining convenient enzymes from four different organisms into a synthetic butanol pathway expressed in E. coli [27]. The use of a 2-keto-acid decarboxylase of low substrate specificity together with an alcohol dehydrogenase into a modified $E$. coli strain produces high yields of isobutanol by the 2-keto-acid pathway $[25,31,32]$. The 2-keto-acid pathway of Corynebacterium glutamicum has also been engineered, taking advantage of the high amino-acid production characteristic of this bacteria [28].

In summary, reviewing the main strategies used for biobutanol production in bacteria (Table 1) several conclusions arose. First, using natural producers, the 
best strategies are those based in selection of strains and fermentation conditions in combination with product recovery techniques that may avoid toxicity [18]; or those that increase fuel concentration by avoiding the production of acetone [21] or deviate this metabolite to the production of isopropanol [22]. These approaches allow a two to ten folds increase of achieved fuel concentration in comparison to the original, not engineered, strains of Clostridium acetobutylicum. The introduction of the metabolic pathway for $\mathrm{ABE}$ fermentation in other bacteria, considered advantageous because they do not require anaerobic fermentations, grow faster or are more tolerant to butanol, has been less successful since the reached concentration of fuel are far below those obtained for the natural producers $[17,25,26]$. A promising area is the engineering of non-natural producer bacteria with the 2-keto-acid pathway, which has increased more than two folds the fuel concentration in comparison to natural strains of Clostridium acetobutylicum [25].

\section{Engineered pathways in yeasts}

Although in hitherto published papers engineered Clostridia or E. coli show higher yields of biobutanol production than yeasts [33], it has been reported that industry opts for engineered Saccharomyces cerevisae for isobutanol high-scale production systems [2]. One reason may be the good previous operational experience about bioethanol production by this yeast together with the possibility to adapt the same infrastructure. In fact, the companies producing biobutanol by recombinant yeasts are or were bioethanol producers. A visit to the web page http://www.biobutanol.com/ or to those of the companies Gevo, Butamax or Butalco (date of reference 2014-10-06) support these statements. Moreover, there are several drawbacks with the use of bacteria for biobutanol production in industry such as requirement for strictly anaerobic conditions in the Clostridium species, a complex separation process from the fermentation media, narrow and neutral $\mathrm{pH}$ growth rate and susceptibility to phage infections when grown on a large scale $[4,34]$. These drawbacks associated to bacterial fermentations support the use of yeast.

S. cerevisae has the enzymes to synthesize isobutanol by the two-compartment Erhlich pathway, in which ketoisovalerate (an intermediary product of mitochondrial valine biosynthesis) is catabolized into isobutanol in the cytosol, although levels produced naturally are low (Figure 1). The strategies of yeast metabolic engineering employed by different research groups, from academy or industry, to improve biobutanol production (as reviewed by $[2,35])$ are varied and can be summarized as follows: Overexpression of ILV2, ILVS and ILV3, the own genes of the valine biosynthesis pathway encoding acetolactate synthase, ketoacid reductoisomerase and dihydroxyacid dehydratase, respectively; expression of all enzymes involved in isobutanol synthesis into mitochondria using a mitochondrial transport signal; external addition of ketoisovalerate to be converted by heterologous decarboxylases and alcohol dehydrogenases, combined with disruption of the $P D C 1$ gene, encoding pyruvate decarboxilase; expression of the valine biosynthetic pathway in the cytosol by removing the mitochondrial targeting signals of the genes $I L V 2$, ILV5 and ILV3 or introducing heterologous genes, but keeping the mitochondrial pathway intact; replacement of the mitochondrial pathway by a cytosolic pathway to avoid competition, which was got by over-expression of cytosolic forms encoded by ILV2, ILV5, ILV3, ARO10 or other ketoacid decarboxylase, and $A D H 2$ or other alcohol dehydrogenase, together with deletion of mitochondrial $I L V 2$ and the three pyruvate decarboxilase encoding genes (PDC1, PDC5, PDC6); increase of cytosolic acetyl-CoA supply (by expression of the $E$. coli pyruvate dehydrogenase complex) together with reduction of pyruvate decarboxilase endogenous activity and expression of the butanol synthetic pathway from Clostridia. Moreover, additional genetic manipulations were performed to overcome the lack of growth on glucose as single carbon source of the pyruvate decarboxilase mutant (pdc-) strains, to reduce other by-products formation besides ethanol, to increase dihydroxyacid dehydratase (encoded by $\mathrm{ILV} 3$ or heterologous genes) activity, or to correct cofactor imbalance. Combining several of these strategies more than $80 \%$ of the maximum isobutanol theoretical yield was reached. Also, Brat et al. [36] adapted the codon usage of the cytosolic expressed genes of valine biosynthesis to those of the highly expressed genes of glycolysis.

More recently, during the last 2 years (2013-2014) new yeast metabolic engineering approaches have been published that are following summarized. Also, in Table 2 a selection of engineered S. cerevisiae strains, only those producing isobutanol and recently published, is summarized, showing reported yield and/or titer reached.

Branduardi et al. [38] proposed an alternative way based in exploiting the catabolic pathway of amino acids resulting from hydrolysis of proteins, where proteins come from dead microbial biomasses at the end of fermentation. The authors demonstrated how glycine could be the substrate for the synthesis of butanol and isobutanol in S. cerevisiae following the pathway glyoxylate, $\beta$-ethylmalate, $\alpha$-ketovalerate and $\alpha$-ketoisovalerate. No heterologous activities were used.

Krivoruchko et al. [34] reconstructed the 1-butanol biosynthetic pathway in S. cerevisae. This was done by increasing flux towards cytosolic acetyl-CoA by means of the transformation with a plasmid expressing the genes ADH2 (alcohol dehydrogenase), ALD6 (acetaldehyde dehydrogenase), ACS1/ACS2 (acetyl-CoA synthetase), and ERG10 (acetyl-CoA acetyltransferase). Also using null 
Table 2 Metabolic engineering approaches to improve isobutanol production by the yeast S. cerevisiae

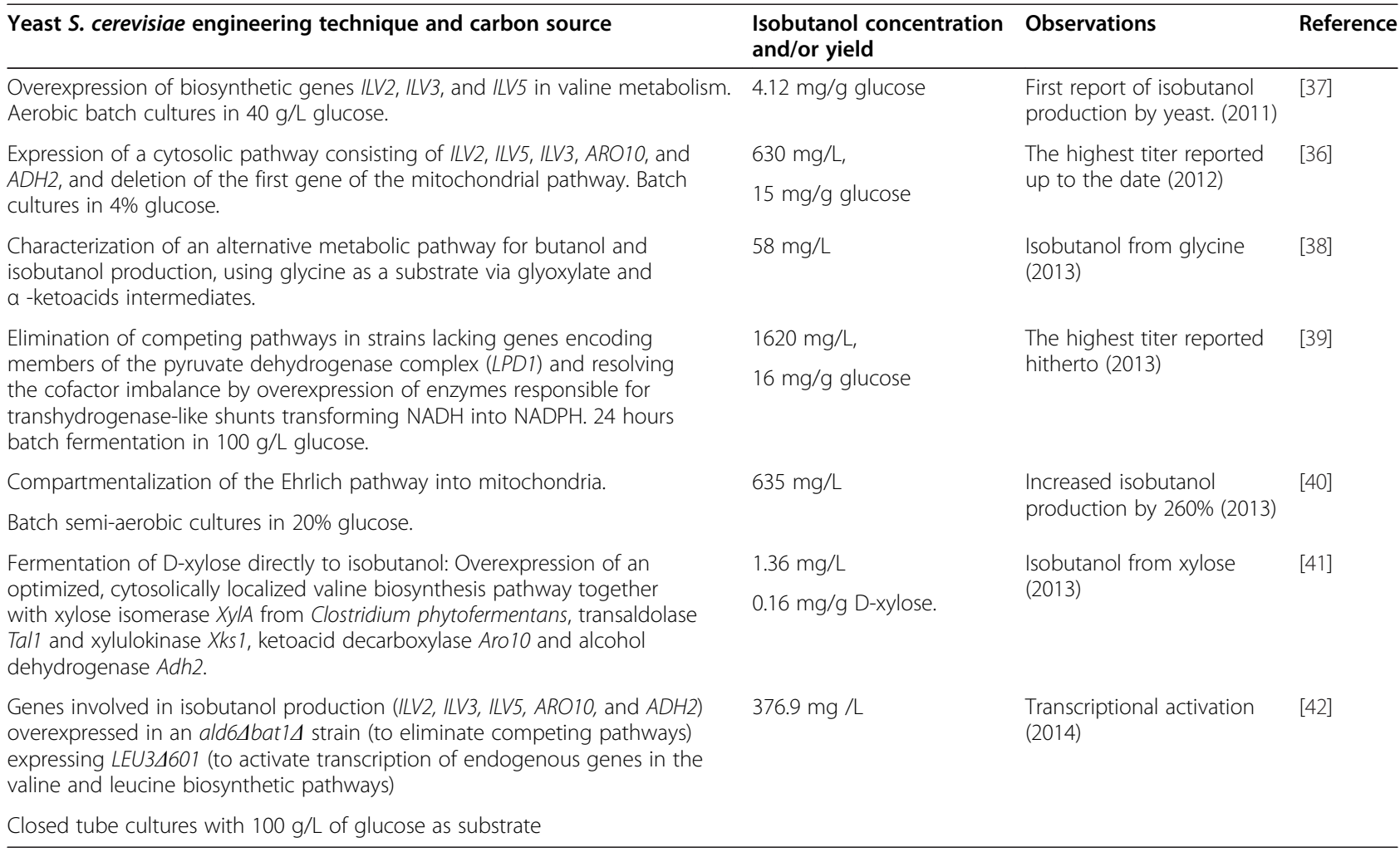

mutant strains for the genes CIT2 (citrate synthase) or MLS1 (malate synthase).

$\mathrm{Si}$ et al. [43] reported the discovery, characterization and engineering of an endogenous 1-butanol pathway in $S$. cerevisiae, dependent on the catabolism of threonine, in a similar way to fusel alcohol production by the Ehrlich pathway. Specifically, the leucine biosynthesis pathway was engaged in the conversion of key 2-keto acid intermediates. Upon introduction of a single gene deletion $a d h 1 \Delta$ (causing deficiency of alcohol dehydrogenase), overexpression of the Ehrlich pathway enzymes and eradication of the competing routes, the highest reported 1-butanol titer by $S$. cerevisiae was achieved $(242.8 \mathrm{mg} / \mathrm{L}$ from glucose as substrate).

Matsuda et al. [39] improved isobutanol yield by $S$. cerevisiae strains lacking genes of the pyruvate dehydrogenase complex such as LPD1, to reduce competition between the pyruvate supply for isobutanol biosynthesis and acetyl-CoA biosynthesis in mitochondria, together with overexpression of enzymes responsible for transhydrogenase-like shunts, converting $\mathrm{NADH}$ to $\mathrm{NADPH}$, such as pyruvate carboxylase, malate dehydrogenase, and malic enzyme, to resolve cofactor imbalance.

Avalos et al. [40] showed that a greater increase in isobutanol synthesis was obtained by compartmentalization of the Ehrlich pathway into mitochondria (about 260\%) than by overexpression of the same pathway in the cytoplasm (about 10\%), in comparison with a strain overproducing the enzymes that catalyze the first three steps of the anabolic route. The expected benefits of mitochondrial compartmentalization are diverse. First, a local increase in enzyme concentration; second, improved availability of intermediates, avoiding the necessity for exporting them outside mitochondria; and third, it reduces the consumption of intermediates by competing routes.

Brat and Boles [41] described the construction of a recombinant $S$. cerevisiae strain able to produce isobutanol directly from D-xylose. Simultaneous over-expression of a cytosolic route of valine biosynthesis and of the three enzymes xylose isomerase from Clostridium phytofermentans, transaldolase and xylulokinase allowed the complementation of the valine auxotrophy of ilv2,3,5 triple deletion mutants and growth on D-xylose as the sole carbon source. The additional over-expression of ARO10 (ketoacid decarboxilase) and $A D H 2$ (alcohol dehydrogenase) conferred the cells the ability to directly ferment D-xylose to isobutanol. This is important because D-xylose can represent over $30 \%$ of plant biomass and in this way the economy of lignocelulosic hydrolysates fermentation processes is improved [44].

Park et al. [42] engineered a leucine auxotrophic strain for the production of isobutanol and 3-methyl-1-butanol from the catabolism of valine and leucine. The authors 
deleted two genes (ALD6 coding for aldehyde dehydrogenase and BAT1 of valine synthesis), and increased transcription of endogenous genes in the biosynthetic routes of these aminoacids, by expressing a constitutively active form of the Leu3 transcriptional activator.

Also, genome-scale and proteomic analysis, and physiological adaptations, have been performed to improve butanol and stress tolerance by yeast [45-47].

An overview of the above cited academic papers describing engineered yeast strains to produce isobutanol (Table 2), comparing the yields and titers obtained with such strains, points out to the strain developed by Matsuda et al. [39] as the highest producer showing a titer of $1620 \mathrm{mg} / \mathrm{L}$ and a yield of $16 \mathrm{mg} / \mathrm{g}$ glucose after 24 hours microaerobic batch fermentation in $100 \mathrm{~g} / \mathrm{L}$ glucose. Although this comparison is difficult to perform since operation time, media and conditions of culture are different in each case, there is a higher difference with other strains in titer (more than double) than in yield since, for example, Brat et al. [36] report a yield of $14.2 \mathrm{mg} / \mathrm{g}$ glucose although with a titer of $630 \mathrm{mg} / \mathrm{L}$ from aerobic batch cultures in $40 \mathrm{~g} / \mathrm{L}$ glucose. During the preparation of this review, Generoso et al. [48] reported a comparison among representative academic yeast strains engineered to produce butanol isomers (1-, 2- and iso-butanol) that supports the same here exposed conclusion.

\section{Cheese whey as substrate for butanol production}

The remaining liquid after extraction of milk casein during cheese manufacturing, cheese whey, is relevant in the dairy industry due to its nutritional composition, since it retains about $55 \%$ of milk nutrients, and is used as additive in food industries. But, the amount produced, about $90-95 \%$ of the milk volume, generates disposal problems, which requires viable solutions [49]. Over 160 million tonnes per year are estimated to be produced in the world, approximately 9-fold the total cheese production, and the tendency is to increase 1-2\% annually [9]. The biochemical oxygen demand (BOD) and the chemical oxygen demand (COD) of cheese whey are $35,000 \mathrm{ppm}$ and a $68,000 \mathrm{ppm}$ respectively [50]. Only a half of total world cheese whey production is transformed into various food products [51] and therefore other uses are necessary to cope out with the problem.

Whey valorisation is generally initiated by diafiltration or ultrafiltration to recover whey protein concentrates (WPC), which have many applications in the food industry $[9,52]$. During these processes large volumes of a lactoserich stream are also generated. Indeed, lactose, being 70\% of total whey solids, contributes largely to the whey polluting load [9]. The utilization of lactose present in whey or permeates is possible through fermentation to ethanol or butanol $[9,51]$.

\section{Lactose metabolism in Clostridium}

Several strains of Clostridium acetobutylicum and Clostridium beijerinckii have been used to produce butanol by fermentation of whey. However, most of these studies $(88.88 \%$ of the works analyzed in this review) were focused on strains of $C$. acetobutylicum. Although relatively little is currently known about the bioconversion of lactose into butanol, several works about molecular characterization of lactose transport and metabolism in C. acetobutylicum ATCC 824 strain (the C. acetobutylicum most employed strain to ferment the whey, $50 \%$ of the studies reported here used this strain) have been published recently [53,54]. In this strain, lactose is taken up via the phosphoenol-pyruvate (PEP)-dependent phosphotransferase system (PTS), which catalyzes the concomitant uptake and phosphorylation and deposits the resulting phosphorylated derivative, lactose 6-phosphate, in the cytoplasm. Lactose 6-phosphate is hydrolyzed to glucose and galactose- 6 -phosphate by a phospho- $\beta$-galactosidase (Figure 2). Glucose may be phosphorylated and metabolized to pyruvate via the normal glycolytic pathway and the galactose-6-phosphate is generally metabolized to triose phosphates by the tagatose6-phosphate pathway [53]. Both PTS and phospho- $\beta$ galactosidase are only induced during growth in lactose, but are absent in glucose-grown cells. Moreover, this strain exhibited a classical diauxic growth, in glucose and lactose medium the lac operon is not expressed until glucose is consumed. Therefore, lactose transport and metabolism in this strain seemed to be under the control of a catabolite responsive element characteristic of low-GC gram-positive bacteria [53].

Other C. acetobutylicum strains, different from $C$. acetobutylicum ATCC 824, such as $C$. acetobutylicum P262 (the second C. acetobutylicum most employed strain to ferment the whey, $43.75 \%$ of the studies reported here used this strain), NCIB 2951, NRRL 594, NRRL 598 and NRRL 2490, were shown to contain $\beta$-galactosidase besides of phospho- $\beta$-galactosidase activities when grown in lactose medium [55], and a $\beta$-galactosidase gene has been cloned from strain NCIB 2951 [56]. These Clostridia probably possess a non-PTS mediated transport mechanism and lactose is transported through the cell membrane by a lactose permease (Figure 2), together with PTS uptake [57]. The galactose released from the hydrolysis of lactose by the $\beta$-galactosidase is metabolized by the Leloir pathway [54,57]. Interestingly, during the fermentation of whey permeate by these strains, the induction of phospho- $\beta$-galactosidase was associated with the acidogenic phase, whereas the $\beta$-galactosidase was induced in the solvent production phase [55].

Recently, genomic information on C. beijerinckii NCIMB 8052, the other main species used in the fermentation of whey $(11.11 \%$ of the works analyzed in this review), has 
A

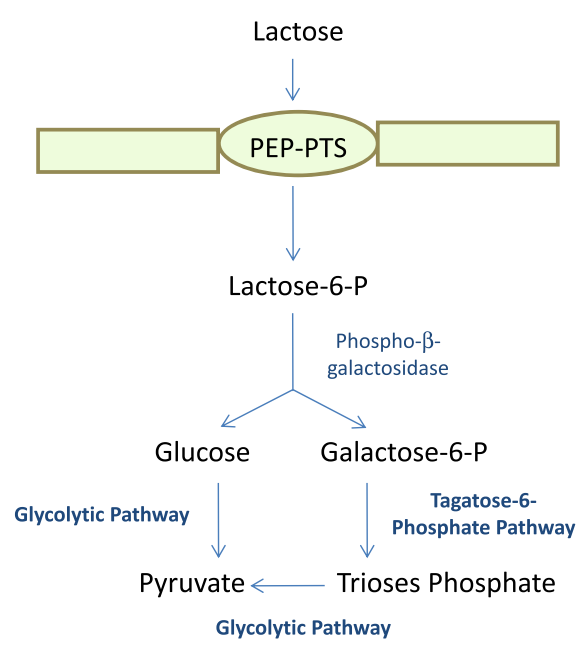

B

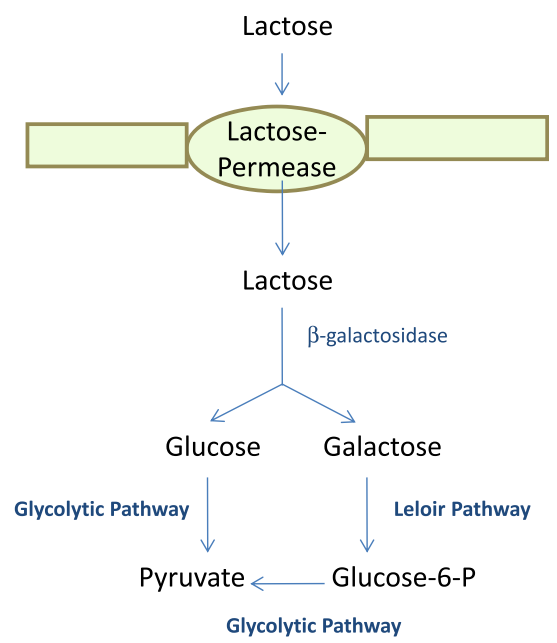

Figure 2 Schematic representation of the different lactose transport and utilization by Clostridium species. A) Phosphoenol-pyruvate (PEP)-dependent phosphotransferase system (PTS) pathway and B) Lactose permease pathway.

been published [58]. This strain shows the presence of 47 PTS genes apparently involved in the metabolism of complex carbohydrates, including multiple genes whose protein products are putatively involved in lactose transport and metabolism [58]. Therefore, it has been proposed that lactose metabolism in C. beijerinckii NCIMB 8052 could be similar to C. acetobutylicum ATCC 824 [59].

All these studies about the genetics and physiology of lactose uptake and metabolism in Clostridium species could have theoretical and practical importance to improve the butanol production from milk whey based on manipulation of these strains and the optimizations of fermentation conditions.

\section{Lactose utilization by Saccharomyces cerevisae}

Although S. cerevisiae is usually the first choice for industrial processes, it is unable to metabolizee lactose. Nevertheless, S. cerevisiae can uptake galactose by a permease coded by the GAL2 gene. Once, inside the cell, galactose can be further metabolized by the Leloir pathway. Thus, the first attempts to ferment cheese whey by $S$. cerevisiae were based on the pre-hydrolysis of lactose with $\beta$-galactosidase [60] or the use of a biocatalyst consisting of yeast co-immobilized with $\beta$-galactosidase $[61,62]$, but these processes have limited applicability due to the diauxic growth showed by $S$. cerevisiae in glucose and galactose media. To circumvent this problem, 2-deoxyglucose was used as a selection agent to isolate catabolite repression-resistant mutants of $S$. cerevisiae [63], which were able of using glucose and galactose simultaneously.

Genetic engineering techniques allowed the heterologous expression in S. cerevisiae of the $\beta$-galactosidase and lactose permease genes from Kluyveromyces lactis, performing an intra-cellular hydrolysis of the lactose. Earlier developed recombinant strains were genetically unstable and grew slowly in lactose [64]. Both characteristics have been improved in the later developed strains [65-67].

Other approximation to create lactose-consuming $S$. cerevisiae (Lac+) strains consisted in the production by protoplast fusion of hybrids strains of $S$. cerevisiae and Kluyveromyces spp. [68]. The construction of recombinant $S$. cerevisiae strains secreting the extracellular $\beta$-galactosidase from Aspergillus niger to the medium [69-71] or S. cerevisiae expressing and secreting $K$. lactis $\beta$-galactosidase $[72,73]$ were also reported. In addition, approximations based on the release of intracellular heterologous $\beta$-galactosidase (e.g. from Escherichia coli or $K$. lactis) by other means different of secretion have been studied [74,75], also including the use of $S$. cerevisiae osmotic-remedial thermosensitive autolytic mutants [76,77] and cell permeabilization with toluene or ethanol [78].

However, in spite of the interesting work done, most of these studies were focused on the fermentation of cheese whey to ethanol. None of the strategies employed or the recombinant $S$. cerevisae strains generated have been used hitherto to test the butanol production from cheese whey.

\section{Production of butanol by the fermentation of cheese whey by Clostridium}

The relatively low sugar content in whey (lactose $40-50 \mathrm{~g} / \mathrm{L}$ ) is generally a disadvantage for its use in fermentation processes and requires prior concentration. However this value is near to optimal for the acetonebutanol-ethanol (ABE) fermentation, in which product inhibition limits the amount of sugar consumed. This, altogether with the ability of $C$. acetobutylicum to ferment 
lactose directly, reveals whey (or whey permeate) as an attractive alternative substrate for the ABE fermentation. Several authors have outlined the value of cheese-whey for butanol production using various Clostridium species and whey types for solvent production in conventional batch fermentation using free cells, and also in continuous fermentation. Although most of the reports were published during the 1980's and 1990's, the butanol production from cheese-whey is gaining increasing interest during the last ten years. A brief summary of that is following reported.

\section{Batch production of butanol from whey permeate}

Maddox [79] fermented sulphuric acid whey filtrate using C. acetobutylicum NCIB 2951. The whey filtrate contained $53 \mathrm{~g} / \mathrm{L}$ lactose and, after being supplemented with $5 \mathrm{~g} / \mathrm{L}$ yeast extract, was adjusted to $\mathrm{pH} 6.5$ and sterilized. A butanol concentration of $15 \mathrm{~g} / \mathrm{L}$ was obtained after 5 days incubation at $30^{\circ} \mathrm{C}$. The ratio of Acetone:Butanol:Ethanol solvents obtained was 1:10:1. If the yeast extract was not added, only $13 \mathrm{~g} / \mathrm{L}$ butanol was obtained after 7 days incubation.

The effect of whey sterilization by autoclaving prior to batch fermentation using C. acetobutylicum ATCC 824 and the effect of agitation were shown to be important variables with respect to the solvent ratio produced and the yield obtained [80]. Generally, agitation was detrimental to solvent production with unsterilized and sterilized whey. Moreover, the correlation between lactose utilization rate and solvent yield was negative [81]. Thus, in order to favor solventogenesis against acidogenesis, it is necessary to select conditions such as low culture $\mathrm{pH}$ values or high initial lactose concentrations.

The influence of variations in inoculum pretreatment, medium composition, $\mathrm{pH}$ and fermentation temperature on butanol fermentation using whey ultrafiltrate with $C$. beyerinckii LMD 27.6 were also investigated [82]. A decrease in the temperature from $37^{\circ} \mathrm{C}$ to $30^{\circ} \mathrm{C}$ greatly raised the concentration of butanol produced and the total amount of lactose fermented from whey ultrafiltrate. Variations of inoculum pretreatment, yeast extract concentration and $\mathrm{pH}$ had no effects on butanol production at $37^{\circ} \mathrm{C}$. The overall product yields $[(\mathrm{kg}$ butanol $+\mathrm{kg}$ isopropanol) $/(\mathrm{kg}$ carbohydrated utilized)] were comparable between whey ultrafiltrate and glucose medium. But the batch reactor mean productivity $(\mathrm{kg} / \mathrm{L} \cdot \mathrm{h})$, including the lag phase, lowered 2-3 folds whether comparing permeate (lactose) with glucose. The lag phase was longer and substrate conversion rate slower for the permeate fermentations.

Mixtures of glucose and galactose, present in hydrolyzed whey, were also tested in fermentation processes [82]. Although a preference for glucose was observed, glucose/galactose mixtures could be used for butanol production.
One interesting observation in the use of whey as the substrate for fermentation is the unusually high ratio butanol/acetone. Bahl et al. [83] reported that the fermentation of whey using various $C$. acetobutylicum strains yielded a butanol:acetone ratio of approximately 100:1. This ratio decreased to 2:1 when synthetic media with only glucose as carbon source was used. The difference in the solvent ratios obtained on these two media, was attributed to the more favourable growth conditions in the whey medium; in particular, the presence of lactic acid and an intrinsically optimum concentration of iron supply that is growth limiting and favors butanol production.

In spite of the work done, in general, whey (or whey permeate) has proved to be a relatively poor substrate when overall reactor productivity in batch fermentation is considered, if compared with starch and molasses substrates [84]. This and the incomplete utilization of lactose, are the two major problems of using whey as a substrate. Since the concentrations of total solvents produced are lower than those produced on conventional substrates, product inhibition does not appear to play a main role in the poor production of acetone and butanol from whey. Most solventogenic strains can tolerate a maximum level of total ABE of $20 \mathrm{~g} / \mathrm{L}$ [85] and $32.6 \mathrm{~g} / \mathrm{L}$ [86] for the genetically manipulated hiper-solvent producing strain, $C$. beijerinckii BA101. At these solvent concentrations, the fermentation is completely inhibited. The maximum total $\mathrm{ABE}$ reported up to now by strains fermenting whey was $17 \mathrm{~g} / \mathrm{L}$ [79].

Besides product inhibition, ABE fermentation is affected by other factors such as inhibition by substrate or salt concentration. It is also diminished by dead cells increase, nutrient deficiency, low water activity, accumulation of polysaccharides and other macromolecules, or undesired $\mathrm{O}_{2}$ losses in connecting tubes that are produced during the feeding of nutrients into the fermentor $[5,87,88]$. Remarkably, high concentrations (about 200 g/ L) of whey permeate (lactose) did not cause substrate inhibitory effect [87], opposite to glucose that showed inhibitory effects at concentrations greater than $161 \mathrm{~g} / \mathrm{L}$ [88].

More recently, Foda et al. [89] investigated the suitability of lactose containing substrates in batch fermentation using C. acetobutylicum DSM 792 and $C$. acetobutylicum AS 1.224. In aerobic conditions, using lactose medium, C. acetobutylicum DSM 792 was better for solvents production than AS 1.224 in laboratory conditions. In bioreactor batch experiments, using lactose and cheese whey media, these authors demonstrated that cheese whey is an excellent substrate for biobutanol production with clear advantages respect to lactose medium $(1.5 \mathrm{~g} / \mathrm{L}$ of butanol production in cheese whey media versus $0.71 \mathrm{~g} / \mathrm{L}$ of butanol in lactose medium). 
Another inexpensive non-whey-lactose-based substrate, milk dust powder, for $\mathrm{ABE}$ fermentation was evaluated recently [59]. Milk dust is a blend of different milk powders left over after industrial milk packaging with high lactose content. Batch fermentation of milk dust powder by $C$. acetobutylicum and C. beijerinckii produced 7.3 and $5.8 \mathrm{~g} / \mathrm{L}$ of butanol respectively and, similar to previous reports for whey [83], both species favors butanol production over acetone compared to fermentation with glucose.

\section{Continuous production of butanol from whey permeate}

Butanol was produced continuously from whey permeate using cells of $C$. beijerinckii LMD 27.6, immobilized in calcium alginate beads [90]. The best production parameters in these conditions were $30^{\circ} \mathrm{C}$ during fermentation and a dilution rate of $0.1 \mathrm{~h}^{-1}$ or less during the start-up phase. In these conditions the reactor productivities were sixteen times higher than those obtained in batch cultures using free $C$. beijerinckii cells grown on whey media.

Production of solvents from whey permeate was also achieved using adsorbed cells of $C$. acetobutylicum onto bonechar in a packed bed reactor (PBR) in continuous that was operated for 61 days maintaining stable conditions [91]. The maximum solvent productivity $(4.1 \mathrm{~g} / \mathrm{L} \cdot \mathrm{h})$ was reached at a dilution rate of $1.0 \mathrm{~h}^{-1}$; this value represents a yield of $0.23 \mathrm{~g}$ solvent/g lactose utilized. Solventogenesis was favoured at high concentrations of lactose in the whey permeate, while low concentrations stimulated acidogenesis.

Ennis and Maddox [92] investigated the ABE continuous fermentation of whey permeate using the strain $C$. acetobutylicum P262A. Cells were recycled by using a dispositive able of being backflushed and consisting on a tubular cross-flow microfiltration (CFM) membrane plant. Cyclic solventogenic and acidogenic behaviour was observed along the continuous fermentation. However, finally it changed to a predominantly acidogenic state, with only short periods of steady-state solvent production. Solventogenic or acidogenic behaviour is correlated with specific morphological cell forms; thus vegetative cells produce acid, while clostridial cells produce solvent. It has been suggested that is necessary to maintain a balance among the various morphological cell forms (vegetative, clostridial and spores) in order to maintain steady-state solvent production during a long time. In this report [92] the loss of this necessary balance was attributed to morphological changes of C. acetobutylicum P262A grown on whey permeate.

Also stable biofilms of C. acetobutylicum were prepared for continuous fermentation processes using lactose and yeast extract as substrates; a packed bed reactor, containing hydrophobic plastic carriers was prepared and best results of fermentation were obtained by increasing dilution rate and $\mathrm{pH}[93]$.
Yeast extract is a necessary supplement when using whey permeate as a substrate for solvent production, presumably as a nutrient source; effectively Maddox demonstrated that batch fermentation without this supplement performed less well [79]. Raganati et al. [94] investigated the feasibility of butanol production by C. acetobutylicum DSM 792 by continuous conversion of un-supplemented deproteinized cheese whey. The experiment was performed for more than 3 months in a PBR using Tygon rings as biofilm carriers. The lowest D (dilution rate) investigated gave best performance for the butanol/solvent production. These results were consistent with those reported by Qureshi and Maddox [91], but Raganati [94] obtained better performances when PBRs were operated in absence of yeast extract and with $28 \mathrm{~g} / \mathrm{L}$ lactose in the feeding (under close operating conditions).

An assessment of the growth kinetics [11] and of both the growth and the metabolism [95] of acidogenic cells of C. acetobutylicum DSM 792 were reported. Both tests were carried out under controlled conditions in a continuous stirred tank reactor using a synthetic medium with lactose as carbon source. The proposed models predict the microorganism growth rate [11] or estimate the mass fractional yield [95] under a broad range of operating conditions, including those necessary for solvents production.

\section{Fed-batch and batch culture coupled with an in situ recovery process}

The economic feasibility of classical fed-batch or continuous cultivation is hampered by solvent toxicity and the biphasic performance of acetone-butanol fermentation, respectively. To avoid these problems, in situ recovery processes have been coupled with fed-batch and batch cultures.

Employing silicone membrane and oleyl alcohol as the perstraction solvent, the integrated $\mathrm{ABE}$ fermentation by perstraction was investigated using whey permeate and lactose as substrates [96]. Subsequently, $57.8 \mathrm{~g}$ of $\mathrm{ABE}$ were produced with ABE productivity of $0.24 \mathrm{~g} / \mathrm{L}$. . The membrane allowed butanol diffusion into the extractant, but diffusion of acetone and acids were limited, which resulted in a higher ABE yield of $0.37 \mathrm{~g} / \mathrm{g}$ due to acid re-assimilation.

A batch fermentation process coupled with simultaneous product removal by gas stripping has been assayed [87]. In this way, a semi-synthetic medium containing lactose up to $200 \mathrm{~g} / \mathrm{L}$ has been completely fermented by C. acetobutylicum P262 to $70 \mathrm{~g} / \mathrm{L}$ of ABE.

An integrated system coupled with liquid-liquid extraction significantly enhanced lactose utilization from whey permeate, using C. acetobutylicum P262 immobilized cells in a fluidized bed bioreactor, with feeble reduction in productivity [97].

Later, Qureshi and Maddox [98] coupled ABE production from whey permeate medium supplemented with lactose, 
using C. acetobutylicum P262 in a batch reactor, with ABE removal by perstraction. $136.6 \mathrm{~g} / \mathrm{L}$ of $\mathrm{ABE}$ were produced from $313.3 \mathrm{~g} / \mathrm{L}$ lactose with a yield of $0.44 \mathrm{~g} / \mathrm{g}$ and productivity of $0.21 \mathrm{~g} / \mathrm{L} h$. Using ABE removal by perstraction, the ratio of acids to solvents was significantly lower than in the control batch process, thus indicating the conversion of acids into solvents.

The butanol productivity (g/L h) and the butanol concentration $(\mathrm{g} / \mathrm{L})$ were chosen to compare the works analyzed in this section (Figure 3). The references [83] and [95] were not included in the Figure 3 because data do not allow comparable calculations. The highest butanol productivity $(2.7 \mathrm{~g} / \mathrm{L} \mathrm{h})$ was reached with $C$. acetobutylicum P262 immobilized by adsorption onto bonechar growing in whey permeate supplemented with yeast extract in a continuous PBR [91], followed $(2.66 \mathrm{~g} / \mathrm{L} \mathrm{h})$ by $C$. acetobutylicum DSM 792 growing in un-supplemented deproteinized cheese whey in a continuous PBR [94]. The highest butanol concentration $(15 \mathrm{~g} / \mathrm{L})$ was obtained after 5 days incubation by $C$. acetobutylicum NCIB 2951 growing in acid whey filtrate supplemented with yeast extract in batch mode [79] followed (14.64 g/L) by C. acetobutylicum DSM 792 growing in synthetic medium supplemented with lactose in continuous stirred tank reactor [11]. In general, batch fermentation gave poor productivity and continuous fermentation processes with C. acetobutylicum DSM 792 strain (corresponds to ATCC 824) gave better performance both in butanol productivity and butanol concentration. However, the industrial hurdle rate estimate of $5 \mathrm{~g} / \mathrm{L} \mathrm{h}$ of butanol productivity [99] is far to achieve. Overall, the results support the view that further investigation of whey (permeate) as a substrate for the ABE fermentation is desirable.

\section{Conclusion and perspectives}

The increasing attractive of biobutanol as fuel reveals new opportunities for the utilization of by-products from the dairy industry. The utilization of whey for biobutanol production has been scarcely explored, although this is a desirable objective. Several plants producing bioethanol from whey are operating [9] and the combined production of bioethanol and biobutanol could improve the economic interest and also contribute to obtain a more efficient biofuel. Considering that production of biofuels is a useful mean to slow down carbon dioxide emissions, this is also a green-industry with ecological benefits to humankind and that could contribute to decrease present concerns over global climate change.

The production of biobutanol from whey is theoretically possible since solventogenic Clostridia are able to grow with lactose as carbon source, and direct assays of this production are here reviewed. Proteins, which are as well major components of whey composition, could even be considered as substrates for biobutanol production. Recently an E. coli strain was engineered to grow on 13 amino acids as the unique carbon source and it was able to produce $406 \mathrm{mg} / \mathrm{L}$ of bio-alcohols (isobutanol, 2-methyl butanol, and 3-methyl butanol) from yeast extract [100].

The establishment of advanced biofuel production from whey sources is still a developing field and a long way remains to be run. Fortunately new tools and strategies are available nowadays to speed the process. Strain development by engineering microorganisms with the appropriate pathways and pathway optimization, eliminating bottlenecks and avoiding toxicity, are now assisted by the "omics" technology and the systems biology approach. New strategies might be used to optimize synthetic combined enzyme activity and the resulting metabolic flux by the "co-localization" concept. The co-localization of diverse proteins participating in the pathway can be achieved in the cell either by enzyme fusion, directed protein trafficking, or the use of scaffolding proteins. All these possibilities have been thoroughly reviewed [101] and could be applied to successful biobutanol production from whey in the near future.

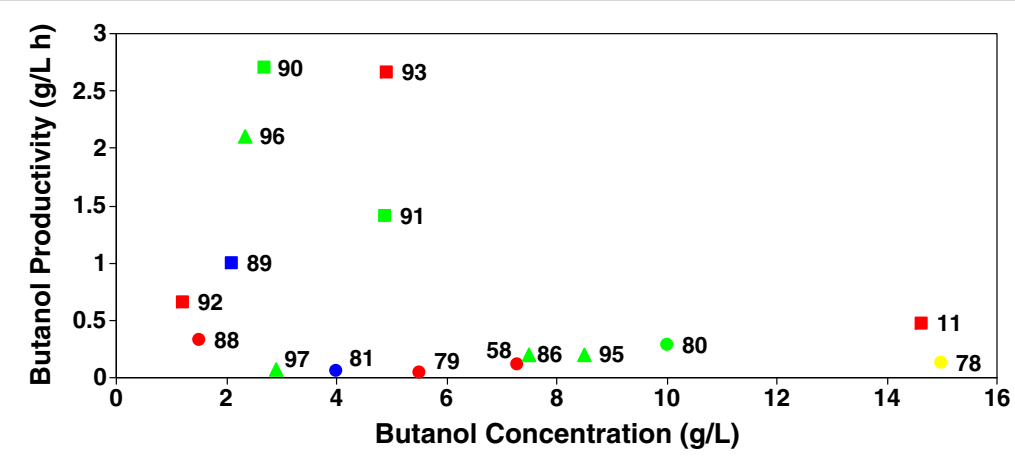

Figure 3 Butanol productivity (g/L h) versus Butanol concentration (g/L) of Clostridium species growing on lactose medium. Circle: Batch fermentation; Square: Continuous fermentation; Triangle: Fermentation coupled with an in situ recovery process. Green: C. acetobutylicum P262 strain; Red: C. acetobutylicum ATCC 824 strain; Yellow: C. acetobutylicum NCIB 2951 strain; Blue: C. beijerinckii. Numbers: references. 


\section{Competing interests}

The authors declare that they have no competing interests.

\section{Authors' contributions}

MB, MEC and MIGS performed the literature review and contributed to the analysis and the drafting of the manuscript. All authors read and approved the final manuscript.

\section{Acknowledgements}

General support to the laboratory during 2012-14 was funded by Xunta de Galicia (Consolidación D.O.G. 10-10-2012. CN: 2012/118), also financed by FEDER.

\section{Received: 7 October 2014 Accepted: 26 January 2015 Published online: 05 March 2015}

\section{References}

1. Durre P. Biobutanol: an attractive biofuel. Biotechnol J. 2007;2(12):1525-34.

2. Hong K, Nielsen J. Metabolic engineering of Saccharomyces cerevisiae: A key cell factory platform for future biorefineries. Cell Mol Life Sci. 2012;69(16):2671-90

3. Peralta-Yahya PP, Zhang F, Del Cardayre SB, Keasling JD. Microbial engineering for the production of advanced biofuels. Nature. 2012;488(7411):320-8.

4. Xue C, Zhao X, Liu C, Chen L, Bai F. Prospective and development of butanol as an advanced biofuel. Biotechnol Adv. 2013;31(8):1575-84.

5. Kumar M, Gayen K. Developments in biobutanol production: New insights. Appl Energy. 2011;88(6):1999-2012.

6. Pfromm PH, Amanor-Boadu V, Nelson R, Vadlani P, Madl R. Bio-butanol vs. bio-ethanol: A technical and economic assessment for corn and switchgrass fermented by yeast or Clostridium acetobutylicum. Biomass Bioenergy. 2010;34(4):515-24.

7. Green EM. Fermentative production of butanol-the industrial perspective. Curr Opin Biotechnol. 2011;22(3):337-43.

8. Stankus T. Reviews of Science for Science Librarians: Microbes that Make Biofuels and Work within Fuel Cells. Sci Technol Libraries. 2014;33(1):71-88.

9. Guimarães PMR, Teixeira J, Domingues L. Fermentation of lactose to bio-ethanol by yeasts as part of integrated solutions for the valorisation of cheese whey. Biotechnol Adv. 2010;28(3):375-84.

10. Huang H, Liu H, Gan YR. Genetic modification of critical enzymes and involved genes in butanol biosynthesis from biomass. Biotechnol Adv. 2010;28(5):651-7.

11. Napoli F, Olivieri G, Russo M, Marzocchella A, Salatino P. Continuous lactose fermentation by Clostridium acetobutylicum - Assessment of acidogenesis kinetics. Bioresour Technol. 2011;102(2):1608-14.

12. Napoli F, Olivieri G, Marzocchella A, Salatino P. Bioenergy II: An assessment of the kinetics of butanol production by Clostridium acetobutylicum. Int J Chem React Eng. 2009;7:1608-14.

13. Baer SH, Blaschek HP, Smith TL. Effect of Butanol Challenge and Temperature on Lipid Composition and Membrane Fluidity of Butanol-Tolerant Clostridium acetobutylicum. Appl Environ Microbiol. 1987;53(12):2854-61.

14. Liu S, Qureshi N. How microbes tolerate ethanol and butanol. New Biotechnol. 2009;26(3-4):117-21.

15. Dickinson JR, Harrison SJ, Hewlins MJ. An investigation of the metabolism of valine to isobutyl alcohol in Saccharomyces cerevisiae. J Biol Chem. 1998;273(40):25751-6.

16. Hazelwood LA, Daran JM, van Maris AJ, Pronk JT, Dickinson JR. The Ehrlich pathway for fusel alcohol production: a century of research on Saccharomyces cerevisiae metabolism. Appl Environ Microbiol. 2008;74(8):2259-66.

17. Berezina OV, Zakharova NV, Brandt A, Yarotsky SV, Schwarz WH, Zverlov W. Reconstructing the clostridial n-butanol metabolic pathway in Lactobacillus brevis. Appl Microbiol Biotechnol. 2010;87(2):635-46.

18. Ezeji TC, Qureshi N, Blaschek HP. Production of acetone butanol (AB) from liquefied corn starch, a commercial substrate, using Clostridium beijerinckii coupled with product recovery by gas stripping. J Ind Microbiol Biotechnol. 2007;34(12):771-7.

19. Malaviya A, Jang YS, Lee SY. Continuous butanol production with reduced byproducts formation from glycerol by a hyper producing mutant of Clostridium pasteurianum. Appl Microbiol Biotechnol. 2012;93(4):1485-94.
20. Kopke M, Held C, Hujer S, Liesegang H, Wiezer A, Wollherr A, et al. Clostridium ljungdahlii represents a microbial production platform based on syngas. Proc Natl Acad Sci USA. 2010;107(29):13087-92.

21. Hou X, Peng W, Xiong L, Huang C, Chen X, Chen X, et al. Engineering Clostridium acetobutylicum for alcohol production. J Biotechnol. 2013;166(1-2):25-33.

22. Lee J, Jang YS, Choi SJ, Im JA, Song H, Papoutsakis ET, et al. Metabolic engineering of Clostridium acetobutylicum ATCC 824 for isopropanolbutanol-ethanol fermentation. Appl Environ Microbiol. 2012;78(5):1416-23.

23. Jang YS, Malaviya A, Lee J, Im JA, Lee SY, Lee J, et al. Metabolic engineering of Clostridium acetobutylicum for the enhanced production of isopropanol-butanolethanol fuel mixture. Biotechnol Prog. 2013;29(4):1083-8.

24. Schiel-Bengelsdorf B, Durre P. Pathway engineering and synthetic biology using acetogens. FEBS Lett. 2012;586(15):2191-8.

25. Atsumi S, Liao JC. Metabolic engineering for advanced biofuels production from Escherichia coli. Curr Opin Biotechnol. 2008;19(5):414-9.

26. Nielsen DR, Leonard E, Yoon SH, Tseng HC, Yuan C, Prather KL. Engineering alternative butanol production platforms in heterologous bacteria. Metab Eng. 2009;11(4-5):262-73.

27. Bond-Watts BB, Bellerose RJ, Chang MC. Enzyme mechanism as a kinetic control element for designing synthetic biofuel pathways. Nat Chem Biol. 2011;7(4):222-7.

28. Smith KM, Cho KM, Liao JC. Engineering Corynebacterium glutamicum for isobutanol production. Appl Microbiol Biotechnol. 2010;87(3):1045-55.

29. Gottumukkala LD, Parameswaran B, Valappil SK, Mathiyazhakan K, Pandey A, Sukumaran RK. Biobutanol production from rice straw by a non-acetone producing Clostridium sporogenes BE01. Bioresour Technol. 2013;145:182-7.

30. Lehmann D, Hönicke D, Ehrenreich A, Schmidt M, Weuster-Botz D, Bahl H, et al. Modifying the product pattern of Clostridium acetobutylicum: Physiological effects of disrupting the acetate and acetone formation pathways. Appl Microbiol Biotechnol. 2012;94(3):743-54.

31. Atsumi S, Hanai T, Liao JC. Non-fermentative pathways for synthesis of branched-chain higher alcohols as biofuels. Nature. 2008;451(7174):86-9.

32. Atsumi S, Wu TY, Eckl EM, Hawkins SD, Buelter T, Liao JC. Engineering the isobutanol biosynthetic pathway in Escherichia coli by comparison of three aldehyde reductase/alcohol dehydrogenase genes. Appl Microbiol Biotechnol. 2010;85(3):651-7.

33. Lan ELJ. Microbial synthesis of n-butanol, isobutanol, and other higher alcohols from diverse resources. Bioresour Technol. 2013;135:339-49.

34. Krivoruchko A, Serrano AC, Chen Y, Siewers V, Nielsen J. Improving biobutanol production in engineered Saccharomyces cerevisiae by manipulation of acetyl-CoA metabolism. J Ind Microbiol Biotechnol. 2013;40(9):1051-6.

35. Buijs N, Siewers $V$, Nielsen J. Advanced biofuel production by the yeast Saccharomyces cerevisiae. Curr Opin Chem Biol. 2013;17(3):480-8.

36. Brat D, Weber C, Lorenzen W, Bode H, Boles E. Cytosolic re-localization and optimization of valine synthesis and catabolism enables inseased isobutanol production with the yeast Saccharomyces cerevisiae. Biotechnol Biofuels. 2012;5(1):65.

37. Chen X, Nielsen KF, Borodina I, Kielland-Brandt MC, Karhumaa K. Increased isobutanol production in Saccharomyces cerevisiae by overexpression of genes in valine metabolism. Biotechnol Biofuels. 2011;4:21.

38. Branduardi P, Longo V, Berterame N, Rossi G, Porro D. A novel pathway to produce butanol and isobutanol in Saccharomyces cerevisiae. Biotechnol Biofuels. 2013;6(1):68.

39. Matsuda F, Ishii J, Kondo T, Ida K, Tezuka H, Kondo A. Increased isobutanol production in Saccharomyces cerevisiae by eliminating competing pathways and resolving cofactor imbalance. Microbial Cell Factories. 2013;12(1):119.

40. Avalos JL, Fink GR, Stephanopoulos G. Compartmentalization of metabolic pathways in yeast mitochondria improves the production of branched-chain alcohols. Nat Biotechnol. 2013;31(4):335-41.

41. Brat D, Boles E. Isobutanol production from D-xylose by recombinant Saccharomyces cerevisiae. FEMS Yeast Res. 2013;13(2):241-4.

42. Park S, Kim S, Hahn J. Metabolic engineering of Saccharomyces cerevisiae for the production of isobutanol and 3-methyl-1-butanol. Appl Microbiol Biotechnol. 2014;98:9139-47.

43. Si T, Luo Y, Xiao H, Zhao H. Utilizing an endogenous pathway for 1-butanol production in Saccharomyces cerevisiae. Metab Eng. 2014;22:60-8.

44. Fatehi P. Recent advancements in various steps of ethanol, butanol, and isobutanol productions from woody materials. Biotechnol Prog. 2013;29(2):297-310. 
45. González-Ramos D, Van Den Broek M, Van Maris AJA, Pronk JT, Daran J-G. Genome-scale analyses of butanol tolerance in Saccharomyces cerevisiae reveal an essential role of protein degradation. Biotechnol Biofuels. 2013;6(1):48.

46. Ghiaci P, Norbeck J, Larsson C. Physiological adaptations of Saccharomyces cerevisiae evolved for improved butanol tolerance. Biotechnol Biofuels. 2013;6:101.

47. Xue C, Zhao JB, Chen LJ, Bai FW, Yang ST, Sun JX. Integrated butanol recovery for an advanced biofuel: current state and prospects. Appl Microbiol Biotechnol. 2014;98:3463-74.

48. Generoso WC, Schadeweg V, Oreb M, Boles E. Metabolic engineering of Saccharomyces cerevisiae for production of butanol isomers. Curr Opin Biotechnol. 2015:33:1-7.

49. Spalatelo C. Biotechnological valorisation of whey. Innov Roman Food Biotechnol. 2012;10:1-8.

50. Dahiya M. VS: Comparative analysis of bioethanol production from whey by different strains of immobilized thermotolerant yeast. Int J Scie Res Publ. 2012;2:1-5.

51. González Siso MI. The biotechnological utilization of cheese whey: A review. Bioresour Technol. 1996;57(1):1-11.

52. Smithers G. Whey and whey proteins_From 'gutter-to-gold'. Int Dairy J. 2008;18(7):695-704.

53. Yu Y, Tangney M, Aass HC, Mitchell WJ. Analysis of the mechanism and regulation of lactose transport and metabolism in Clostridium acetobutylicum ATCC 824. Appl Environ Microbiol. 2007;73(6):1842-50.

54. Servinsky MD, Kiel JT, Dupuy NF, Sund CJ. Transcriptional analysis of differential carbohydrate utilization by Clostridium acetobutylicum. Microbiology. 2010;156(11):3478-91.

55. Yu P, Smart JB, Ennis BM. Differential induction of $\beta$-galactosidase and phospho- $\beta$-galactosidase activities in the fermentation of whey permeate by Clostridium acetobutylicum. Appl Microbiol Biotechnol. 1987;26(3):254-7.

56. Hancock KR, Rockman E, Young CA, Pearce L, Maddox IS, Scott DB. Expression and nucleotide sequence of the Clostridium acetobutylicum B-galactosidase gene cloned in Escherichia coli. J Bacteriol. 1991;173(10):3084-95.

57. Patakova P, Linhova M, Rychtera M, Paulova L, Melzoch K. Novel and neglected issues of acetone-butanol-ethanol (ABE) fermentation by clostridia: Clostridium metabolic diversity, tools for process mapping and continuous fermentation systems. Biotechnol Adv. 2013;31(1):58-67.

58. Shi Y, Li Y-X, Li Y-Y. Large number of phosphotransferase genes in the Clostridium beijerinckii NCIMB 8052 genome and the study on their evolution. BMC Bioinformatics. 2010;11 Suppl 11:S9.

59. Ujor V, Bharathidasan AK, Cornish K, Ezeji TC. Evaluation of industrial dairy waste (milk dust powder) for acetone-butanol-ethanol production by solventogenic Clostridium species. SpringerPlus. 2014;3:387.

60. Mehaia MA, Cheryan M. Ethanol from hydrolyzed whey permeate using Saccharomyces cerevisiae in a membrane recycle bioreactor. Bioprocess Eng. 1990;5(2):57-61.

61. Hahn-Hagerdal B. Comparison between immobilized Kluyveromyces fragilis and Saccharomyces cerevisiae coimmobilized with $\beta$-galactosidase, with respect to continuous ethanol production from concentrated whey permeate. Biotechnol Bioeng. 1985;27(6):914-6.

62. Staniszewski M, Kujawski W, Lewandowska M. Semi-continuous ethanol production in bioreactor from whey with co-immobilized enzyme and yeast cells followed by pervaporative recovery of product - Kinetic model predictions considering glucose repression. J Food Eng. 2009;91(2):240-9.

63. Bailey RB, Benitez T, Woodward A. Saccharomyces cerevisiae mutants resistant to catabolite repression: Use in cheese whey hydrolysate fermentation. Appl Environ Microbiol. 1982;44(3):631-9

64. Sreekrishna K, Dickson RC. Construction of strains of Saccharomyces cerevisiae that grow on lactose. Proc Natl Acad Sci U S A. 1985;82(23):7909-13.

65. Rubio-Texeira M, Castrillo J, Adam AC, Ugalde UO, Polaina J. Highly efficient assimilation of lactose by a metabolically engineered strain of Saccharomyces cerevisiae. Yeast. 1998;14(9):827-37.

66. Domingues $L$, Teixeira JA, Lima N. Construction of a flocculent Saccharomyces cerevisiae fermenting lactose. Appl Microbiol Biotechnol. 1999:51(5):621-6.

67. Guimarães PMR, François J, Parrou JL, Teixeira JA, Domingues L. Adaptive evolution of a lactose-consuming Saccharomyces cerevisiae recombinant. Appl Environ Microbiol. 2008;74(6):1748-56.
68. Tahoun MK, El-Nemr TM, Shata OH. A recombinant Saccharomyces cerevisiae strain for efficient conversion of lactose in salted and unsalted cheese whey into ethanol. Nahrung - Food. 2002;46(5):321-6.

69. Kumar V, Ramakrishnan S, Teeri TT, Knowles JKC, Hartley BS. Saccharomyces cerevisiae cells secreting an Aspergillus niger $\beta$-galactosidase grow on whey permeate. Bio/Technology. 1992;10(1):82-5.

70. Domingues L, Teixeira J, Penttilä M, Lima N. Construction of a flocculent Saccharomyces cerevisiae strain secreting high levels of Aspergillus niger $\beta$-galactosidase. Appl Microbiol Biotechnol. 2002;58(5):645-50.

71. Oliveira C, Teixeira JA, Lima N, Da Silva NA, Domingues L. Development of stable flocculent Saccharomyces cerevisiae strain for continuous Aspergillus niger $\beta$-galactosidase production. J Biosci Bioeng. 2007;103(4):318-24.

72. Becerra M, Díaz Prado S, Cerdán E, González Siso MI. Heterologous Kluyveromyces lactis $\beta$-galactosidase secretion by Saccharomyces cerevisiae super-secreting mutants. Biotechnol Lett. 2001;23(1):33-40.

73. Becerra M, Díaz Prado S, González Siso MI, Cerdán ME. New secretory strategies for Kluyveromyces lactis ß-galactosidase. Protein Eng. 2001;14(5):379-86.

74. Compagno C, Porro D, Smeraldi C, Ranzi BM. Fermentation of whey and starch by transformed Saccharomyces cerevisiae cells. Appl Microbiol Biotechnol. 1995;43(5):822-5.

75. Porro D, Martegani E, Ranzi BM, Alberghina L. Lactose/whey utilization and ethanol production by transformed Saccharomyces cerevisiae cells. Biotechnol Bioeng. 1992;39(8):799-805.

76. Becerra M, Cerdán E, González Siso MI. Heterologous Kluyveromyces lactis $\beta$-galactosidase production and release by Saccharomyces cerevisiae osmotic-remedial thermosensitive autolytic mutants. BBA - General Subjects. 1997;1335(3):235-41.

77. Becerra M, Rodríguez-Belmonte E, Cerdán ME, González Siso MI. Engineered autolytic yeast strains secreting Kluyveromyces lactis $\beta$-galactosidase for production of heterologous proteins in lactose media. J Biotechnol. 2004;109(1-2):131-7.

78. Compagno C, Tura A, Ranzi BM, Martegani E. Bioconversion of lactose/whey to fructose diphosphate with recombinant Saccharomyces cerevisiae cells. Biotechnol Bioeng. 1993;42(3):398-400.

79. Maddox IS. Production of n-butanol from whey filtrate using Clostridium acetobutylicum N.C.I.B. 2951. Biotechnol Lett. 1980;2(11):493-8.

80. Welsh FW. Production of acetone - butanol from acid whey. Biotechnol Lett. 1984;6(1):61-4

81. Ennis BM. The effect of $\mathrm{pH}$ and lactose concentration on solvent production from whey permeate using Clostridium acetobutylicum. Biotechnol Bioeng. 1987;29(3):329-34

82. Schoutens $\mathrm{GH}$. Butanol from whey ultrafiltrate: Batch experiments with Clostridium beyerinckii LMD 27.6. Appl Microbiol Biotechnol. 1984;19(4)):203-6.

83. Bahl H, Gottwald M, Kuhn A, Rale V, Andersch W, Gottschalk G. Nutritional Factors Affecting the Ratio of Solvents Produced by Clostridium acetobutylicum. Appl Environ Microbiol. 1986;52(1):169-72.

84. Jones DT. Acetone-butanol fermentation revisited. Microbiol Rev. 1986:50 (4):484-524

85. Maddox IS. The acetone-butanol-ethanol fermentation: recent progress in technology. Biotechnol Gen Eng Rev. 1988;7:189-220.

86. Chen C, Blaschek HP. Acetate enhances solvent production and prevents degeneration in Clostridium beijerinckii BA101. Appl Microbiol Biotechnol. 1999:52(2):170-3

87. Maddox IS. Production of Acetone-Butanol-Ethanol from Concentrated Substrates Using Clostridium acetobutylicum in an Integrated Fermentation-Product Removal Process. Process Biochem. 1995;30(3):209-15.

88. Ezeji TC, Qureshi N, Blaschek HP. Acetone butanol ethanol (ABE) production from concentrated substrate: reduction in substrate inhibition by fed-batch technique and product inhibition by gas stripping. Appl Microbiol Biotechnol. 2004;63(6):653-8.

89. Foda MI, Dong H, Li Y. Study the suitability of cheese whey for bio-butanol production by Clostridia. J Am Sci. 2010;6:39-46.

90. Schoutens $\mathrm{GH}$. Continuous butanol production from whey permeate with immobilized Clostridium beyerinckii LMD 27.6. Appl Microbiol Biotechnol. 1985;21(5):282-6.

91. Qureshi N, Maddox IS. Continuous solvent production from whey permeate using cells of Clostridium acetobutylicum immobilized by adsorption onto bonechar. Enzyme Microb Technol. 1987;9(11):668-71.

92. Ennis BM, Maddox IS. Production of solvents (ABE fermentation) from whey permeate by continuous fermentation in a membrane bioreactor. Bioprocess Eng. 1989;4(1):27-34. 
93. Napoli F. Production of butanol in a continuous packed bed reactor of Clostridium acetobutylicum. Chem Eng Trans. 2010;20:193-8.

94. Raganati F, Olivieri G, Procentese A, Russo ME, Salatino P, Marzocchella A. Butanol production by bioconversion of cheese whey in a continuous packed bed reactor. Bioresour Technol. 2013;138:259-65.

95. Napoli F, Olivieri G, Russo M, Marzocchella A, Salatino P. Continuous lactose fermentation by Clostridium acetobutylicum-Assessment of energetics and product yields of the acidogenesis. Enzyme Microb Technol. 2012:50(3):165-72.

96. Qureshi N. Application of continuous substrate feeding to the ABE fermentation: Relief of product inhibition using extration, perstaction, stripping, and pervaporatiinto. Biotechnol Prog. 1992;8(5):382-90.

97. Qureshi N, Maddox I. Continuous production of acetone-butanol-ethanol using immobilized cells of Clostridium acetobutylicum and integration with product removal by liquid-liquid extraction. J Ferment Bioeng. 1995;80(2):185-9.

98. Qureshi N, Maddox IS. Reduction in Butanol Inhibition by Perstraction. Food Bioprod Process. 2005;83(1 C):43-52.

99. Sethaku M, Heitmann S, Górak A, Wichmann R. Investigation of gas stripping and pervaporation for improved feasibility of two-stage butanol production process. Bioresour Technol. 2013;136:102-8.

100. Huo YX, Cho KM, Rivera JG, Monte E, Shen CR, Yan Y, et al. Conversion of proteins into biofuels by engineering nitrogen flux. Nat Biotechnol. 2011;29(4):346-51.

101. Kung Y, Runguphan W, Keasling JD. From fields to fuels: recent advances in the microbial production of biofuels. ACS Synth Biol. 2012;1(11):498-513.

\section{Submit your next manuscript to BioMed Central and take full advantage of:}

- Convenient online submission

- Thorough peer review

- No space constraints or color figure charges

- Immediate publication on acceptance

- Inclusion in PubMed, CAS, Scopus and Google Scholar

- Research which is freely available for redistribution 